\title{
Ethylmalonic/Adipic Aciduria: Effects of Oral Medium-Chain Triglycerides, Carnitine, and Glycine on Urinary Excretion of Organic Acids, Acylcarnitines, and Acylglycines
}

\author{
PIERO RINALDO, ROY D. WELCH, STEPHEN F. PREVIS, EBERHARD SCHMIDT- \\ SOMMERFELD, J. JAY GARGUS, JOHN J. O'SHEA, ARTHUR B. ZINN
}

\begin{abstract}
Department of Genetics, Yale University, New Haven, Connecticut 06510 [P.R., R.D.W., S.F.P., J.J.O.]; Department of Pediatrics, University of Chicago, Chicago, Illinois 60637 [E.S-S.]; Department of Physiology and Section of Medical Genetics, Emory University, Atlanta, Georgia 30322 [J.J.G.]; and Departments of Pediatrics and Genetics, Case Western Reserve University, Cleveland, Ohio 44106 [A.B.Z.]
\end{abstract}

\begin{abstract}
A 9-y-old girl with ethylmalonic/adipic aciduria was hospitalized to determine the possible therapeutic efficacy of oral carnitine and glycine supplementation. To provoke a mild metabolic stress, her diet was supplemented with $440 \mathrm{mg} / \mathrm{kg} / \mathrm{d}$ of medium-chain triglycerides. She was treated successively with carnitine $(100 \mathrm{mg} / \mathrm{kg} / \mathrm{d})$ for $5 \mathrm{~d}$, neither carnitine nor glycine for $2 \mathrm{~d}$, and then glycine $(250 \mathrm{mg} / \mathrm{kg} / \mathrm{d})$ for $6 \mathrm{~d}$. Consecutive 12-h urine collections were obtained throughout the entire period. The urinary excretion of eight organic acids, four acylglycines, and four acylcarnitines, which accumulate as a result of a metabolic block of five mitochondrial acyl-CoA dehydrogenases, were quantitatively determined by capillary gas chromatography, stable isotope dilution gas chromatography/mass spectrometry, and radioisotopic exchange HPLC, respectively. The excretion of each group of metabolites was calculated as the mean percentage of total output $(\mu \mathrm{mol} / 24 \mathrm{~h})$ during the four phases of the protocol (organic acids/acylglycines/acylcarnitines $=100.0 \%): 1$ ) regular diet $(3 \mathrm{~d}) ; 88.1 / 10.8 / 1.1 ; 2)$ medium-chain triglyceride supplementation $(4) ; 82.5 / 15.6 / 1.9 ; 3)$ medium-chain triglycerides plus carnitine (5); 79.2/8.2/12.6; and 4) medium-chain triglycerides plus glycine $(6) ; 81.0 / 18.7 / 0.3$. Comparison between total and individual excretion of acylglycines and acylcarnitines indicates that oral glycine supplementation enhanced the conjugation and excretion of fatty acyl-CoA intermediates as efficiently as carnitine. We propose that oral glycine supplementation should be considered in the treatment of other inborn errors of metabolism associated with abnormal urinary excretion of acylglycines. (Pediatr Res 30: 216-221, 1991)
\end{abstract}

Abbreviations

AC, acylcarnitines

AG, acylglycines

BC, butyrylcarnitine

BG, butyrylglycine

ETF, electron transfer flavoprotein

ETF-QO, ETF-ubiquinone oxidoreductase

HC, hexanoylcarnitine

HG, hexanoylglycine

Received February I3, 1991; accepted May 13, 1991.

Correspondence and reprint requests: Piero Rinaldo, M.D., Yale University School of Medicine, Department of Genetics, 333 Cedar Street, P.O. Box 3333, New Haven, CT 06510-8005.

Supported in part by grants (DK-29911 and DK-17453) from National Institutes of Health and a grant (I-378) from March of Dimes.
IVC, isovalerylcarnitine

IVG, isovalerylglycine

MCT, medium-chain triglyceride

OC, octanoylcarnitine

SG, suberylglycine

ETF and ETF-QO sequentially transfer electrons from several mitochondrial flavin-dependent dehydrogenases to the main mitochondrial respiratory chain (1). An inherited defect of either one of these enzymes causes episodes of hypoglycemia and hypoketotic acidosis in association with three different clinical pictures: severe, neonatal onset with congenital anomalies; severe, neonatal onset without congenital anomalies; and mild later onset (2).

Both ETF and ETF-QO deficiency result in inhibition of several metabolic pathways (fatty acids, lysine, and branchedchain amino acids) at the respective acyl-CoA dehydrogenase step and induce intermittent urinary excretion of dicarboxylic acids (1, 3-5) and acylconjugates (4-9). Although the pattern of organic acid excretion is highly variable, either glutaric acid or ethylmalonic acid and adipic acid are the major components when a diagnostic profile is detected in a given urine sample. Thus, these diseases have been designated as either glutaric aciduria type II (3) or ethylmalonic/adipic aciduria (6).

Several AG have been identified in urine from patients with different organic acidurias (10). Increased excretion of these AG derives presumably from transacylation of the corresponding acyl-CoA that accumulate in these disorders. In urine from patients with ETF or ETF-QO deficiency, excretion of at least five $A G$ is increased: $B G$, isobutyrylglycine, $I G V, H G$, and $S G$ $(1,4-7)$

The presence and diagnostic significance of specific AC has been evaluated in a number of inborn errors of metabolism (8). In patients with organic acidurias, a relative carnitine insufficiency may occur, secondary to conversion and urinary excretion of accumulated acyl-CoA moieties as AC (9). An impairment of carnitine uptake by tissues may also contribute to producing secondary carnitine deficiency (9). A specific profile of urinary $\mathrm{AC}$ has been described in patients with ETF or ETF-QO deficiency, including $\mathrm{BC}$, isobutyrylcarnitine, IVC, HC, and OC (8).

Patients with several organic acidurias have been treated with large oral doses of carnitine $(11,12)$. The use of glycine for therapeutic purposes has been limited to investigations of patients with isovaleric acidemia, in whom it was found to be 
clinically beneficial (13-17). The relative lack of recent interest in glycine supplementation may reflect the assumption that endogenous glycine biosynthesis is active enough not to require exogenous supplementation, regardless of chronic losses via urinary excretion of pathologic $A G$.

In this study, we first induced a mild metabolic stress (dietary MCT oil supplementation) in a 9-y-old girl with a proven deficiency of ETF-QO whose urinary organic acid profile was consistent with the biochemical phenotype of ethylmalonic/adipic aciduria (6). We then investigated the effects of either carnitine or glycine oral supplementation on organic acid and acylconjugate excretion in continuous 24-h urine collections over a period of $20 \mathrm{~d}$. The aim of this study was to determine the relative efficacy of oral carnitine versus oral glycine supplementation to enhance the removal of intracellular acyl-moieties that accumulate as result of multiple metabolic blocks in fatty acid and amino acid metabolism.

\section{MATERIALS AND METHODS}

Case report. The patient reported on here was the first to be diagnosed with ethylmalonic/adipic aciduria (6). Her primary defect is a mild form of ETF-QO deficiency (18\% residual activity) (2).

During the last $3 \mathrm{y}$, she has been in satisfactory condition without any hospitalizations of medical problems. She has been on a low fat (15\% of total calories) and low protein $(1.1-1.2 \mathrm{~g} /$ $\mathrm{kg} / \mathrm{d}, 15 \%$ of caloric intake) diet. At the time of the last physical examination (September, 1989), her height and weight were $168.4 \mathrm{~cm}$ (75th to 90 th percentile) and $57.0 \mathrm{~kg}$ (50th to $75 \mathrm{th}$ percentile), respectively. No sign of neurologic handicaps and no hepatomegaly were found. Her intelligence quotient was in the normal range.

Clinical research protocol. The protocol was approved by the Yale Human Investigation Committee (HIC no. 1430), and informed parental consent was obtained for administration of MCT oil and oral carnitine and glycine supplementation. At 9 y of age (December 1981), she was admitted to the Yale Children's Clinical Research Center for $22 \mathrm{~d}$. Her height and weight were $133 \mathrm{~cm}$ and $31.2 \mathrm{~kg}$, respectively. After $3 \mathrm{~d}$ on a hospital diet adjusted to her caloric needs, her diet was supplemented with $440 \mathrm{mg} / \mathrm{kg} / \mathrm{d}$ of MCT oil (4.6 g three times a day during meals) to provoke a mild metabolic stress. One dose was $1 / 9$ of the amount, used in a previous study (6), that had induced severe vomiting and lethargy $45 \mathrm{~min}$ after ingestion. This diet was well tolerated. On d 6, however, a tentative increase of the MCT oil to $575 \mathrm{mg} / \mathrm{kg} / \mathrm{d}(18.0 \mathrm{~g})$ led to the onset of postprandial nausea, vomiting, and abdominal pain after the second administration. The protocol was continued at the lower dosage (total MCT dose on $\mathrm{d} 6: 16.6 \mathrm{~g}$ or $530 \mathrm{mg} / \mathrm{kg} / \mathrm{d}$ ). She promptly recovered and, from that point on, tolerated the MCT oil well.

Beginning on $\mathrm{d} 8$, she was treated with oral carnitine supplementation $(100 \mathrm{mg} / \mathrm{kg} / \mathrm{d}$ in three divided doses) for $5 \mathrm{~d}$ (only one dose the 1st day), given $15 \mathrm{~min}$ before meals, mixed with orange or apple juice. On d 13, after the end of the carnitine supplementation, she presented the symptoms of a viral infection with mild fever $\left(38^{\circ} \mathrm{C}\right)$, general malaise, nausea, and vomiting. To avoid the risk of more severe symptoms, MCT oil was withdrawn from her diet for $2 \mathrm{~d}$. She ate poorly for these $2 \mathrm{~d}$ and had inadequate caloric intake. On d 15, after complete clinical recovery, the MCT oil was reintroduced and glycine supplementation was added $(250 \mathrm{mg} / \mathrm{kg} / \mathrm{d}$ in three divided doses), the latter given $30 \mathrm{~min}$ before meals. Soon after glycine supplementation was started, the patient appeared to be more energetic and her appetite improved significantly, as did her interest and performance in scholastic duties. None of these changes were noted during the period of carnitine supplementation. On the day after the conclusion of the protocol, however, the patient suffered the same symptoms described above but in a more severe form.
After $1 \mathrm{~d}$ of observation, she recovered and was discharged in good condition.

With the exception of d 13-14, her dietary intake was relatively consistent. Her caloric intake during d 3-12 and 15-20 was 60 $\pm 14 \mathrm{kcal} / \mathrm{kg} / \mathrm{d}$, with protein, fat, and carbohydrate representing the source of $8.7 \pm 2,23.6 \pm 4$, and $67.6 \pm 4.9 \%$ of total calories, respectively.

After the conclusion of this clinical investigation protocol, the patient was started on chronic glycine therapy $(150 \mathrm{mg} / \mathrm{kg} / \mathrm{d})$, which was discontinued approximately 2 y later. During this period, she suffered few or no medical problems, and distinct improvements in her school performance and social interaction were observed. The reported reason for discontinuing glycine supplementation was the patient's refusal to comply with any restrictions or therapeutic measures.

Organic acid analysis. For organic acid and acylconjugate determination, 40 consecutive 12 -h urine collections were pooled at $4^{\circ} \mathrm{C}$ until the end of each period and stored at $-20^{\circ} \mathrm{C}$. Quantitative determinations were performed by capillary gas chromatography using pentadecanoic acid $(100 \mu \mathrm{g})$ as internal standard (18). Results are expressed as $\mu \mathrm{mol} / 24 \mathrm{~h}$.

Carnitine and $A C$ analysis. Free carnitine and individual $\mathrm{C}_{2-}$ $\mathrm{C}_{4}$ carnitine esters were quantitated as described earlier (19), except that extraction and purification of the urine before radioisotopic exchange were omitted. Complete exchange of radiolabeled carnitine into short-chain $\mathrm{AC}\left(\mathrm{C}_{2}-\mathrm{C}_{4}\right)$ was verified after adding various concentrations of authentic standards to the reaction mixtures. In two of the urine samples collected during carnitine supplementation, isobutyrylcarnitine and $\mathrm{BC}$ were separated by HPLC using a different solvent system (20). Two $\mathrm{C}_{5-}$ $\mathrm{AC}$ were also detected after incubation at $37^{\circ} \mathrm{C}$ for $4 \mathrm{~h}$. One of them coeluted with the pure standard of IVC. The other had a longer retention time. No attempt was made to characterize further or quantitate these compounds. For the quantitation of $\mathrm{HC}$ and $\mathrm{OC}$, a known amount of decanoylcarnitine was added as internal standard (21).

$A G$ analysis. $\mathrm{HG}$ and $\mathrm{SG}$ were analyzed by stable isotope dilution analysis as previously described $(7,22)$. Butyryl $\left[1,2-{ }^{13} \mathrm{C}\right]$ glycine was synthesized from butyrylchloride and $\left[1,2-{ }^{13} \mathrm{C}\right] \mathrm{gly}-$ cine. $\left[4,4,4-D_{3}\right]$ IVG was already available from a previous study (23). To quantitate BG and IVG, the initial temperature of the gas chromatography method was $130^{\circ} \mathrm{C}$.

Amino acid analysis. Glycine determination was performed using a Beckman 7300 amino acid analyzer equipped with a lithium 10-cm column (24).

\section{RESULTS}

Organic acid excretion. Figure $1 A-D$ shows the profiles of urinary organic acids in four samples corresponding to the urine collections of $\mathrm{d} 6,12,17$, and 21 (acute episode a day after the termination of the protocol), respectively. The peaks marked 1 to 8 correspond to the eight metabolites (ethylmalonic acid, methylsuccinic acid, and $\mathrm{C}_{5}-\mathrm{C}_{10}$ dicarboxylic acids) quantitated to express, for the purpose of this study, the total organic acid excretion $(\mu \mathrm{mol} / 24 \mathrm{~h})$. The excretion of glutaric acid, adipic acid, suberic acid, and sebacic acid was smaller on those days that the patient was receiving supplementary glycine (Fig. $1 B$ ) or carnitine (Fig. $1 C$ ) than on those days when she was not (Fig. $1 A$ ). In contrast, the organic acid profile during an acute episode (Fig. $1 D$ ) was similar to a typical profile of glutaric aciduria type II.

The pattern of urinary organic acid excretion during the four phases of the clinical trial (Fig. $2 A$ ) is shown in Figure $2 B-D$. The total organic acid excretion is shown in figure $2 B$. In Figure $2 C$, the total organic acid excretion was subdivided into three groups, expressed as the respective percentage in each day: 1 ) ethylmalonic acid plus methylsuccinic acid; 2) glutaric acid; and 3) $C_{6}-C_{10}$ saturated and monounsaturated dicarboxylic acids. The peaks of excretion observed on d 6,13-14, and 20 (Fig. 2B) correlated with the severity of the clinical symptoms. The glutaric 

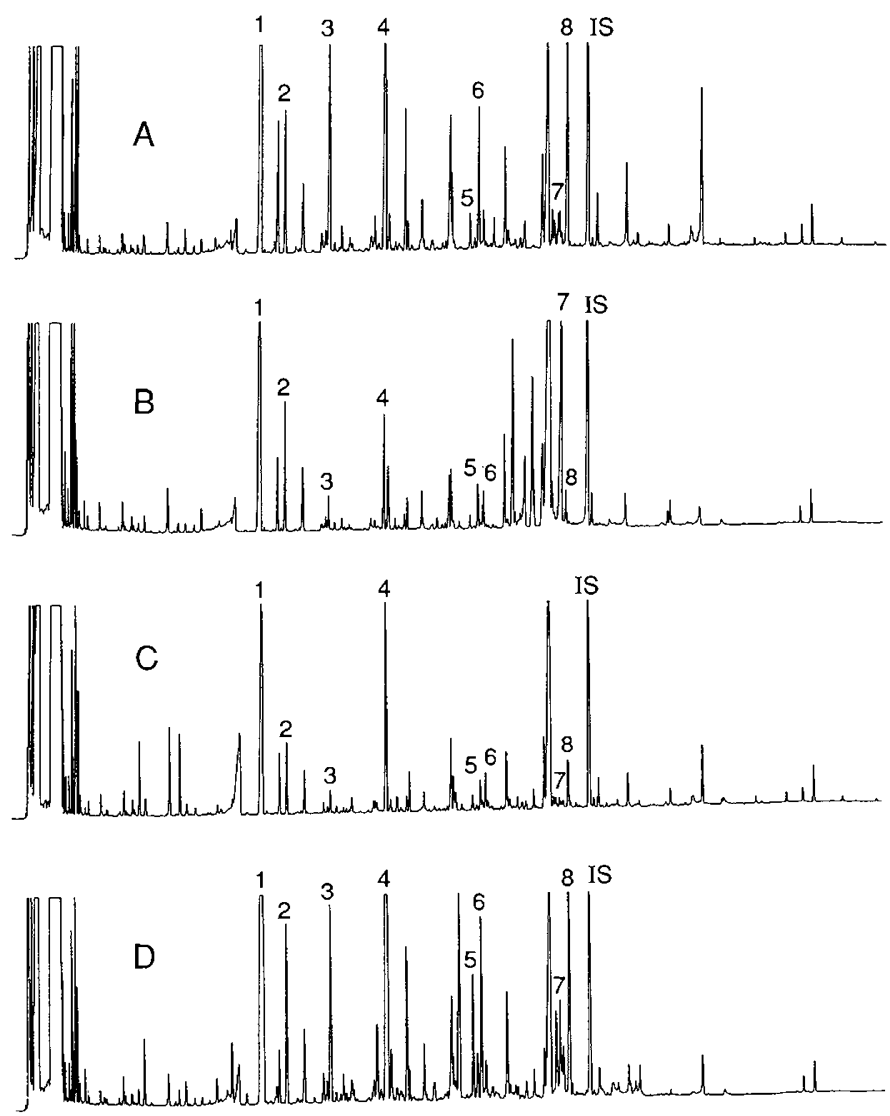

Fig. 1. Organic acid profiles of patient urines. Capillary gas chromatographic profiles of organic acid trimethylsilyl derivatives in four urine samples corresponding to the 0800 - to 2000-h urine collections of $A$, d 6 (MCT $530 \mathrm{mg} / \mathrm{kg} / \mathrm{d}$, mild postprandial symptoms); $B$, d 12 (MCT 440 $\mathrm{mg} / \mathrm{kg} / \mathrm{d}+$ carnitine $100 \mathrm{mg} / \mathrm{kg} / \mathrm{d}$, clinically well); $C$, d 17 (MCT 440 $\mathrm{mg} / \mathrm{kg} / \mathrm{d}+$ glycine $250 \mathrm{mg} / \mathrm{kg} / \mathrm{d}$, clinically well; and $D, \mathrm{~d} 21$ (acute episode after the termination of the protocol). Peak legends: 1 , ethylmalonic acid; 2, methylsuccinic acid; 3, glutaric acid; 4, adipic acid; 5, octenedioic acid (three peaks); 6 , suberic acid; 7 , decenedioic acid (three peaks); 8, sebacic acid; and IS, internal standard (pentadecanoic acid). All peak identifications were confirmed by gas chromatography.

acid excretion was found to be a specific marker of metabolic decompensation, ranging between 0.2 and $2 \%$ of the total organic acid excretion when the patient was clinically well, and up to $22 \%$ during symptomatic episodes.

$A C$ excretion. The $\mathrm{AC}$ excretion pattern is shown in Figures $2 \mathrm{D}$ and $3 . \mathrm{C}_{4}-\mathrm{AC}$ were the major carnitine esters excreted during carnitine supplementation. The total excretion of free carnitine and its esters was subject to marked changes on a day-to-day basis. The average ratio among the $\mathrm{C}_{4} / \mathrm{C}_{6} / \mathrm{C}_{8} \mathrm{AC}$, however, was $85 / 5 / 10(\%)$, with only minor fluctuations during the different phases of the protocol. The average urinary excretion of the AC esters derived from fatty acid oxidation was somewhat increased during MCT feeding as compared with the period of standard diet (Fig. 2D, Table 1), whereas the excretion of free carnitine remained unchanged.

Carnitine supplementation had no significant effect on carnitine ester excretion during the first $36 \mathrm{~h}$ of supplementation, but was followed by a progressive increase of free carnitine and $\mathrm{AC}$ excretion, which reached its peak on the 5th and last day of carnitine supplementation. At that time, the AC fraction accounted for $19 \%$ of the total metabolite excretion. Under glycine supplementation, $\mathrm{AC}$ excretion decreased to less than baseline levels $(\mathrm{BC}+\mathrm{HC}+\mathrm{OC}:<2.0 \mu \mathrm{mol} / 12 \mathrm{~h}$, or $<7.0 \mu \mathrm{mol} / \mathrm{g}$ creatinine).

$A G$ excretion. The $\mathrm{AG}$ excretion pattern is shown in Figure $2 D$. $\mathrm{HG}$ was the prominent $\mathrm{AG}$ in urine, with an average ratio
A)

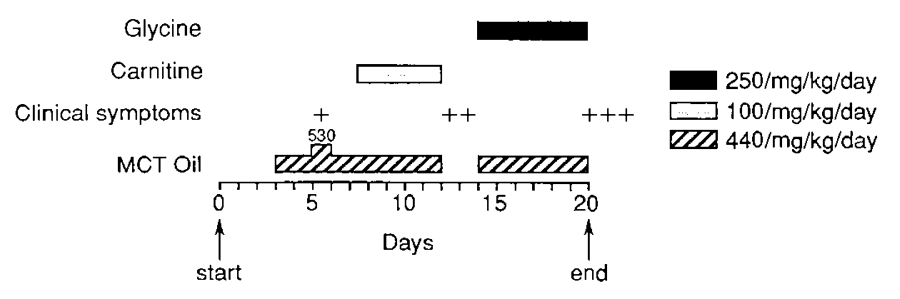

B)

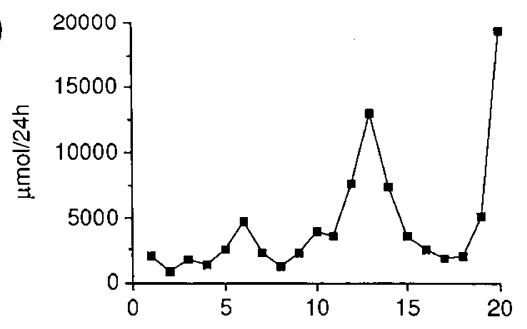

C)

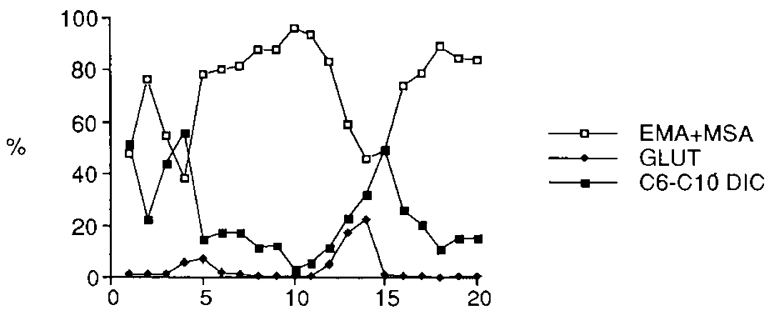

D)

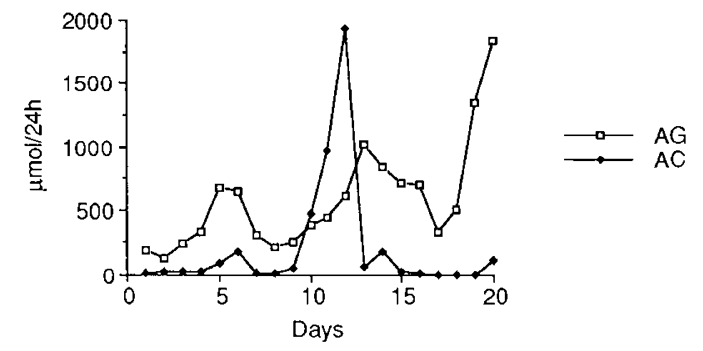

Fig. 2. Time course of organic acid, AG, and $\mathrm{AC}$ excretion. $A$, Periods of MCT oil, carnitine, and glycine oral supplementation during the protocol of clinical investigation. Clinical symptoms (for further details, see text): + , mild; ++ , moderate; and +++ , severe. $B$, Time course of organic acid excretion (sum of metabolites 1 to 8 as listed in the legend to Fig. 1). Values expressed as $\mu \mathrm{mol} / 24 \mathrm{~h}$. $C$, Time course of ethylmalonic acid plus methylsuccinic acid $(E M A+M S A)$, glutaric acid $(G L U T)$, and $\mathrm{C}_{6}-\mathrm{C}_{10}$ saturated and monounsaturated dicarboxylic acid $(C 6-C 10)$ excretion. Values expressed as percentage of the total organic acid excretion. $D$, Time course of $A C$ and $A G$ excretion. Values are expressed as $\mu \mathrm{mol} /$ $24 \mathrm{~h}$.

among the $\mathrm{C}_{4} / \mathrm{C}_{5} / \mathrm{C}_{6} / \mathrm{C}_{8} \mathrm{AG}$ of $6 / 11 / 50 / 33(\%)$ when the patient was on a standard diet, 15/13/40/32 during MCT oil supplementation, and 26/11/40/23 when the patient was receiving MCT + carnitine, respectively (Table 1 ). In contrast to the excretion of the other $\mathrm{AG}, \mathrm{BG}$ excretion increased during carnitine supplementation, in parallel with the pattern of $\mathrm{AC}$ excretion. When glycine was given, the relative excretion of $B G$ further increased with parallel decreases in the proportions of $\mathrm{C}_{5}$ and $\mathrm{C}_{6}$. The average $A G$ ratio during this period was $30 / 10 / 32 / 28$, as determined by analysis of 12 consecutive 12-h urine collections.

For the purpose of comparison with available normal controls, $\mathrm{AG}$ excretion was also calculated as $\mathrm{mmol} / \mathrm{mol}$ of creatinine. $\mathrm{BG}$ (2.4-234.9) and $\mathrm{HG}$ (9.8-168.2) excretion were always above the range of control values: $0.02-1.6$ and $0.13-1.2(8)$, respectively. IVG and $\mathrm{SG}$ excretion were found within the range of controls $(0.21-10.2$ and $<0.005-5.4)$ in 63 and $58 \%$, respectively, of the urine samples. 


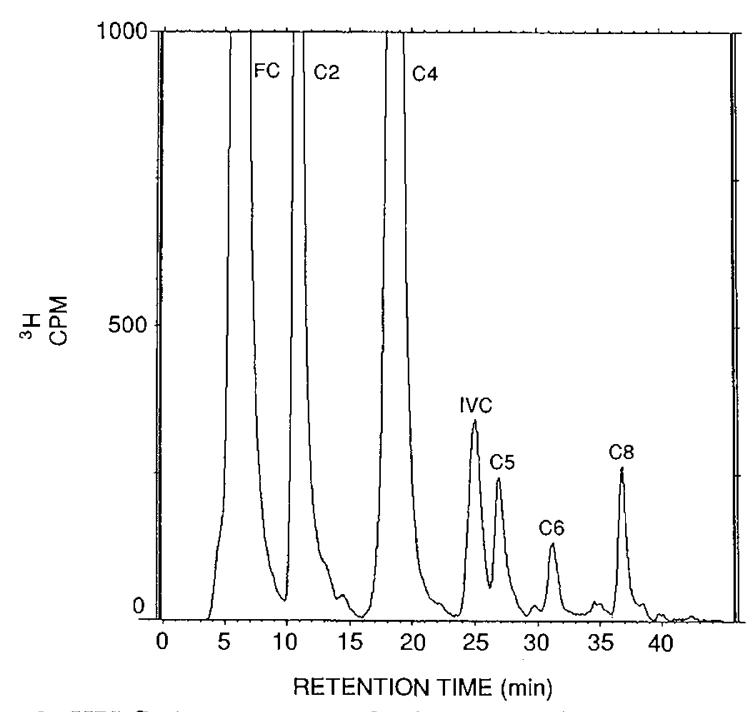

Fig. 3. HPLC chromatogram of urinary carnitine esters. Protile of urinary carnitine esters in the sample corresponding to the 0800- to 2000-h urine collection of d 14. Peak legends: $F C$, free carnitine; $C_{2}$, acetylcarnitine; $C_{4}, \mathrm{BC}(90 \%)$ plus isobutyrylcarnitine (10\%); $I V C$, presumed IVC; $C_{5}$, "other" $\mathrm{C}_{5} \mathrm{AC} ; C_{6}, \mathrm{HC}$; and, $C_{8}, \mathrm{OC}$.

After initiation of glycine supplementation, increased $A G$ excretion was not evident for approximately $24 \mathrm{~h}$. It then increased progressively, reaching a maximum of $28 \%$ of total metabolite excretion. Despite a 10 -fold increase of free glycine excretion compared with the period of standard diet, the ratio of urinary AG/glycine excretion remained unchanged (Table 1).

Because of the unfortunate loss of plasma samples collected during this protocol, plasma glycine values are not available. In a sample collected 6 mo later, glycine concentration was 428.5 $\mu \mathrm{mol} / \mathrm{L}$ (controls: $117-283 \mu \mathrm{mol} / \mathrm{L}$ ). At that time, the patient was receiving glycine $300 \mathrm{mg} / \mathrm{kg} / \mathrm{d}$.

Comparison among organic acids, $A C$, and $A G$ excretion. Table 1 shows the range and median values (in $\mu \mathrm{mol} / 24 \mathrm{~h}$ ) of organic acids, free carnitine, free glycine, and individual $\mathrm{AC}$ and $A G$ excretion during each phase of the protocol. In terms of the absolute amounts of acylconjugates excreted, the results observed with carnitine and glycine supplementation were comparable.
On the last days of supplementation, d 12 and 20, respectively, approximately $2 \mathrm{mmol} / 24 \mathrm{~h}$ of $\mathrm{AC}$ and $\mathrm{AG}$ were excreted (Fig. $2 D$ ). Because a steady state was not reached for acylconjugate excretion with either carnitine or glycine supplementation, no statement can be made about the "maximal" excretion associated with oral carnitine or glycine supplementation in this patient.

Figure 4 shows the comparison (expressed as the percentage of total metabolites) among organic acid, AG, and AC excretion during the four phases of the protocol. Before any supplementation was started, AG excretion accounted for $10 \%$ of total urinary organic acids and acylconjugates and was 10 -fold higher than AC output. As expected, the addition of MCT oil in the diet increased the total excretion of dicarboxylic acids and acylconjugates. However, the relative proportion of dicarboxylic acids, $A C$, and $A G$ remained relatively constant.

To assess further the competition between the two alternative conjugation pathways, the $\mathrm{BG} / \mathrm{BC}$ and $\mathrm{HG} / \mathrm{HC}$ ratios during the entire length of the protocol are presented in Figure 5. The time course of these ratios provides a detailed picture of the role of the two alternative pathways for conjugation of butyryl-CoA and hexanoyl-CoA at any given day of the protocol.

\section{DISCUSSION}

Ethylmalonic/adipic aciduria was considered an appropriate disease model to assess the biochemical effects of both glycine and carnitine supplementation because the disease 1) has an intermittent course with prolonged periods of clinical stability; 2 ) is characterized by a typical organic acid profile; and 3) is associated with pathologic excretion of several AG and AC. We have shown that both oral carnitine and glycine supplementation diverted the disposal of excess acyl-moieties from the $\omega$-oxidation pathway to the synthesis of acylconjugates. Careful quantitative analysis of acyl-group excretion suggests that glycine supplementation may provide a means of treating patients with ETF-QO deficiency that is as efficient as carnitine supplementation. Under a standard diet and during MCT oil supplementation, the detoxification response of this patient was predominantly mediated by glycine rather than carnitine-conjugation of excess mitochondrial acyl-CoA. In relative terms, the AG fraction was 10 - to 20 -fold higher than AC excretion under both a basal diet and MCT oil supplementation and up to 200 -fold higher during glycine sup-

Table 1. Urinary excretion of organic acids, carnitine, glycine, and acylconjugates*

\begin{tabular}{|c|c|c|c|c|c|}
\hline & Standard diet & $\mathrm{MCT}$ & $\begin{array}{l}\text { MCT and } \\
\text { carnitine }\end{array}$ & MCT and glycine & Controls \\
\hline Organic acids & $870-1988(1819)$ & $1452-4702(2423)$ & $1271-7664(3599)$ & $1886-19342(3076)$ & NA \\
\hline Free carnitine & $8-49(13)$ & $8-55(24)$ & $190-2648(794)$ & $4-33(6)$ & $35-127 \dagger$ \\
\hline \multicolumn{6}{|l|}{$\mathrm{AC}$} \\
\hline $\mathrm{AcC}$ & $5-21(11)$ & $24-226(113)$ & $19-884(169)$ & $6-28(9)$ & $9-24$ \\
\hline $\mathrm{C}_{4}$ fraction $\ddagger$ & $6-18(17)$ & $12-153(47)$ & $37-1751(630)$ & $3.0-89(5)$ & $4-6$ \\
\hline $\mathrm{HC}$ & $0.5-0.7(0.5)$ & $0.4-9(1)$ & $1-76(31)$ & $0.6-7(1)$ & ND \\
\hline OC & $1-2(1)$ & $1-19(13)$ & $2-107(58)$ & $0.4-14(1)$ & ND \\
\hline Free glycine & $493-1122(596)$ & $1147-1460(1375)$ & $1602-2155(1955)$ & $4482-9048(6668)$ & $116-1606$ \\
\hline \multicolumn{6}{|l|}{$\mathrm{AG}$} \\
\hline $\mathrm{BG}$ & $8-13(12)$ & $22-103(83)$ & $62-139(103)$ & $114-735(212)$ & NA \\
\hline IVG & $17-26(19)$ & $32-118(63)$ & $20-57(45)$ & $49-122(75)$ & NA \\
\hline $\mathrm{HG}$ & $60-119(94)$ & $110-248(203)$ & $81-248(148)$ & $113-477(233)$ & NA \\
\hline SG & $37-84(66)$ & $93-224(154)$ & $53-212(78)$ & $58-512(203)$ & NA \\
\hline \multicolumn{6}{|l|}{ Ratios§ } \\
\hline $\mathrm{AC} /$ free carnitine & $0.4-1.5(1)$ & $0.4-7.7(2)$ & $0.3-2.9(0.7)$ & $0.9-1.7(1)$ & NA \\
\hline $\mathrm{AG} /$ free glycine & $0.2-0.4(0.2)$ & $0.2-0.5(0.3)$ & $0.1-0.3(0.2)$ & $0.1-0.4(0.2)$ & NA \\
\hline $\mathrm{AG} / \mathrm{AC}$ & $6-25(9)$ & $4-24(12)$ & $0.3-5(0.7)$ & $17-255(74)$ & NA \\
\hline
\end{tabular}

${ }^{*}$ Range and median of values are expressed as $\mu \mathrm{mol} / 24 \mathrm{~h}$. ND, not detectable; NA, not available (see text); AcC, acetylcarnitine.

$\dagger n=3$, age $5-8$ y.

$\$$ Ninety percent $\mathrm{BC}, 10 \%$ isobutyrylcarnitine.

$\S \mathrm{AG}$ and $\mathrm{AC}$ fractions include the metabolites shown above with the exclusion of $\mathrm{AcC}$. AcC was not included in the total $\mathrm{AC}$ excretion because its excretion is not directly dependent on the activity of any enzyme primarily affected by the ETF-QO defect. 


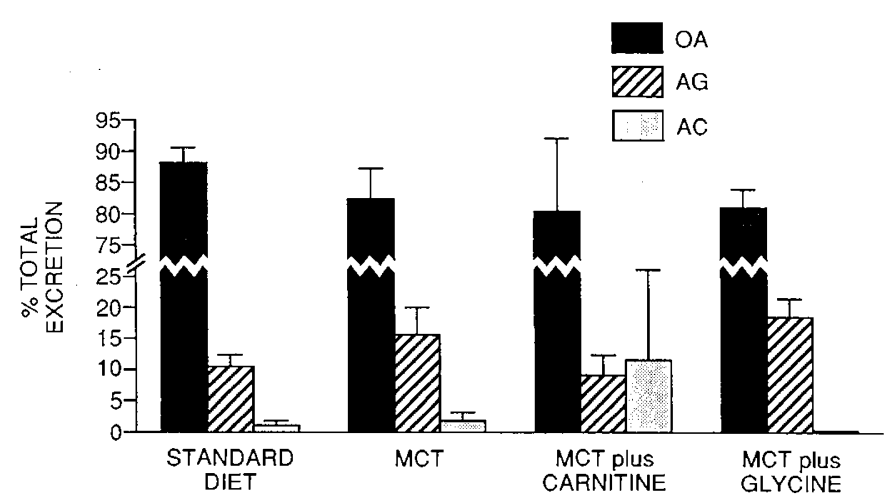

Fig. 4. Relative contributions (\%) or organic acids, AG, and AC to the total metabolite excretion during the four phases of the protocol. The contributions of organic acids $(O A), \mathrm{AG}$, and $\mathrm{AC}$ fractions are shown as mean value and SD (vertical bar) of the total metabolite excretion ( $\mu \mathrm{mol}$ ) $24 \mathrm{~h}$ ) in each of the four phases of the protocol.

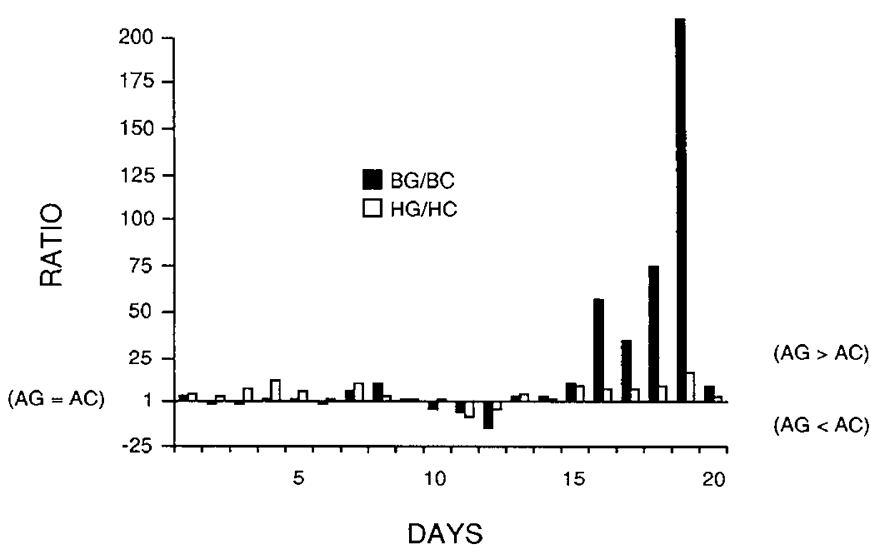

Fig. 5. Time course of $\mathrm{BG} / \mathrm{BC}$ and $\mathrm{HG} / \mathrm{HC}$ ratios. Upward bars indicate that the amount of $\mathrm{BG}$ and $\mathrm{HG}$ was in excess of the respective carnitine ester excretion $(\mu \mathrm{mol} / 24 \mathrm{~h})$ in a given day $(A G>A C)$. Downward bars indicate the opposite situation $(A G<A C)$. $\mathrm{BC}$ values were calculated as $90 \%$ of each $\mathrm{C}_{4}$-AC fraction.

plementation, whereas the median $\mathrm{AC}$ excretion was less than twice the median AG excretion during the period of carnitine supplementation (Fig. 3). The urinary $A G /$ free glycine ratio remained constant throughout the protocol (Table 1), indicating a mass action effect for glycine conjugation. In absolute terms, the excretion of $\mathrm{AC}$ and $\mathrm{AG}$ were comparable on the last days of oral carnitine and glycine supplement.

We observed that free glycine excretion rose after MCT oil was introduced into the diet. Hyperglycinemia/hyperglycinuria had been documented in our patient during earlier episodes of hypoglycemia and acidosis (25). Although we cannot provide an explanation for this reaction to acute episodes and to MCT oil supplementation, it may be related to the accumulation of intracellular acyl-CoA. Although glycine is potentially neurotoxic, patients with ethylmalonic/adipic aciduria (or other inborn errors) are unlikely to reach, after oral glycine supplementation, plasma and cerebrospinal fluid glycine concentrations of the order of magnitude found in nonketotic hyperglycinemia (26).

Until now, the clinical use of glycine supplementation has been limited to patients with isovaleric acidemia $(13-17,27,28)$. Oral glycine supplementation was well tolerated by all of the patients with isovaleric acidemia except one case reported by De Sousa et al. (28), who had onset of encephalopathic features soon after the start of glycine supplementation $(300 \mathrm{mg} / \mathrm{kg} / \mathrm{d})$. In our patient, the same dose induced no symptoms and only a moderate elevation of plasma glycine concentration. Naglak et al. (17) did not observe any side effects in two patients treated with glycine supplementation of $600 \mathrm{mg} / \mathrm{kg} / \mathrm{d}$. Similarly, no side effects have been reported with the use of larger amounts of glycine $(825 \mathrm{mg} / \mathrm{kg} / 6 \mathrm{~h})$ in oral rehydration solutions used for infantile diarrhea in children 5 y of age or younger (29). For these reasons, the adverse reaction described by de Sousa et al. should be seen as the exception rather than the rule. Nevertheless, given the still limited experience with oral glycine supplementation in patients with inborn errors of metabolism, we recommend monitoring plasma glycine levels in patients receiving oral glycine supplementation.

Carnitine has been used widely for the treatment of several organic aciduria, with most of the emphasis placed on disorders of propionate metabolism (9) and fatty acid $\beta$-oxidation (8). However, there is no firm evidence that carnitine supplementation is truly beneficial for patients with individual or multiple acyl-CoA dehydrogenase deficiencies (12). A positive link between enhancement of acylcarnitine excretion and clinical improvement after carnitine therapy sometimes has been assumed rather than documented in patients with secondary carnitine deficiency. In one of the few specific clinical investigation protocols published on this matter, Treem et al. (30) studied a patient with medium-chain acyl-CoA dehydrogenase deficiency and found no improvement in the patient's fasting tolerance after 3 mo of carnitine supplementation.

The combined therapeutic effect of carnitine and glycine supplementation has received little attention. Roe and his associates investigated a 6-mo-old infant with propionic acidemia (31) and a 4-y-old boy with isovaleric acidemia (27). In the first study, a higher threshold of protein tolerance was achieved when the patient was supplemented at the same time with carnitine (100 $\mathrm{mg} / \mathrm{kg} / \mathrm{d})$ and glycine $(150 \mathrm{mg} / \mathrm{kg} / \mathrm{d})$. In the second patient, the excretion of IVG and IVC was determined in response to loading tests with leucine $(25$ and $50 \mathrm{mg} / \mathrm{kg}$ ), leucine plus glycine ( 150 $\mathrm{mg} / \mathrm{kg}$ ) and leucine plus carnitine $(322 \mathrm{mg} / \mathrm{kg})$. When given at the higher dosage without carnitine or glycine, leucine induced nausea and vomiting, but did not do so with concomitant administration of either carnitine or glycine.

Thus, there remains the need to investigate further the potential benefit of glycine in disorders previously found responsive, at least biochemically, to glycine or carnitine supplementation. We propose that glycine supplementation, possibly in combination with carnitine supplementation, should be considered in the treatment of other inborn errors of metabolism distinguished by urinary excretion of pathologic AG.

Acknowledgments. The authors thank Dr. Kay Tanaka, Yale University School of Medicine, for his participation in the initial planning of the clinical investigation protocol and for his comments on a preliminary draft of this manuscript. We also thank Alda Saunders for performing amino acid determinations and for her help in performing gas chromatographic analyses, Denise Alexander for providing expert technical assistance in the carnitine and acylcarnitine analyses, and Lynn Puglisi for giving patient and impeccable secretarial assistance.

\section{REFERENCES}

1. Frerman FE, Goodman Sl 1989 Glutaric acidemia type II and defects of the mitochondrial respiratory chain. In: Scriver CR, Beaudet AL, Sly WS, Valle D (eds) The Metabolic Basis of Inherited Disease, 6th Ed. McGraw-Hill, New York, pp 915-931

2. Loehr JP, Goodman SI, Frerman FE 1990 Glutaric acidemia type II: heterogeneity of clinical and biochemical phenotypes. Pediatr Res 27:311-315

3. Przyrembel H, Wendel U, Becker K, Bremer HJ, Bruinvis L, Ketting D, Wadman SK 1976 Glutaric aciduria type Il: report on a previously undescribed metabolic disorder. Clin Chim Acta 66:227-239

4. Dusheiko G, Kew MC, Joffe BI, Lewin JR, Mantagos S, Tanaka K 1979 Recurrent hypoglycemia associated with glutaric aciduria type $\mathrm{lI}$ in an aduIt. N Engl J Med 301:1405-1409

5. Di Donato S, Frerman FE, Rimoldi M, Rinaldo P, Taroni F. Wiesmann UN 1986 Systemic carnitine deficiency due to lack of electron transfer flavoprotein: ubiquinone oxidoreductase. Neurology 36:957-963

6. Mantagos S, Genel M, Tanaka K 1979 Ethylmalonic-adipic aciduria. In vivo and in vitro studies indicating deficiency of activities of multiple acyl-CoA dehydrogenases. J Clin Invest 64:1580-1589 
7. Rinaldo P, O'Shea JJ, Coates PM, Hale DE, Stanley CA, Tanaka K 1988 Medium chain acyl-CoA dehydrogenase deficiency. Diagnosis by stableisotope dilution measurement of urinary $n$-hexanoylglycine and 3-phenylpropionyl glycine. N Engl J Med 319:1308-1313

8. Roe CR, Coates PM 1989 Acyl-CoA dehydrogenase deficiencies. In: Scrive CR, Beaudet AL, Sly WS, Valle D (eds) The Metabolic Basis of Inherited Disease, 6th Ed., McGraw-Hill, New York, pp 889-914

9. Roe CR, Millington DS, Kahler SG, Kodo N, Norwood DL 1990 Carnitine homeostasis in the organic aciduria. In: Tanaka K, Coates PM (eds) Fatty Acid Oxidation: Clinical Molecular and Molecular Aspects. Alan R Liss, New York, pp 383-402

10. Chalmers RA, Lawson AM 1982 Organic acids in man. In: Analytical Chemistry, Biochemistry and Diagnosis of the Organic Acidurias. Chapman and Hall, London

11. Winter SC, Zorn EM, Vance WH 1990 Carnitine deficiency. Lancet 335:981982

12. Editorial 1990 Carnitine deficiency. Lancet 335:631-633

13. Krieger I, Tanaka K 1976 Therapeutic effects of glycine in isovalericacidemia Pediatr Res 10:25-29

14. Cohn RM, Yudkoff M, Rothman R, Segal S 1978 Isovaleric acidemia: use of glycine therapy in neonates. N Engl J Med 299:996-999

15. Yudkoff M, Cohn RM, Puschak R, Rothman R, Segal S 1978 Glycine therapy in isovaleric acidemia. J Pediatr 92:813-817

16. Velasquez A, Prieto EC 1980 Glycine in acute management of isovaleric acidemia. Lancet 1:313-314

17. Naglak M, Salvo R, Madsen K, Dembure P, Elsas L 1988 The treatment of isovaleric acidemia with glycine supplement. Pediatr Res 24:9-13

18. Rinaldo P, Marcon R, Dussini N, Chiandetti L, Zacchello F, Fois A, Angelin C, Vazzoler G, Parini G 1985 Urinary organic acids in inherited disorders of mitochondrial metabolism. Presumptive differential diagnosis of lactic acidoses by gas chromatography/mass spectrometry. Perspect Inherited Metab Dis 6:53-63

19. Schmidt-Sommerfeld E, Penn D, Kerner J, Bieber LL 1989 Analysis of acylcarnitines in normal human urine with the radioisotopic exchange-high performance liquid chromatography (HPLC) method. Clin Chim Acta $181: 231-238$

20. Bieber LL, Kerner J 1986 Short-chain acylcarnitines: identification and quantitation. Methods Enzymol 123:264-276

21. Schmidt-Sommerfeld E, Penn D, Kerner J, Bieber LL, Rossi TM 1989 Quantitation of urinary carnitine esters in a patient with medium chain acyl-CoA dehydrogenase deficiency: effect of metabolic state and L-carnitine therapy. J Pediatr 115:577-582

22. Rinaldo P, O'Shea JJ, Welch RD, Tanaka K 1989 Stable isotope dilution analysis of $n$-hexanoylglycine, 3-phenylpropionylglycine and suberylglycine in human urine using chemical ionization gas chromatography/mass spectrometry selected ion monitoring. Biomed Environ Mass Spectrom 18:471477

23. Hine DG, Hack AM, Goodman SI, Tanaka K 1986 Stable isotope dilution analysis of isovalerylglycine in amniotic fluid and urine and its application for the prenatal diagnosis of isovaleric acidemia. Pediatr Res 20:222-226

24. Lee PLY, Slocum RH 1988 A high-resolution method for amino acid analysis of physiological fluids containing mixed disulfides. Clin Chem 34:719-723

25. Tanaka K, Mantagos S, Genel M, Seashore MR, Billings BA, Baretz BH 1977 New defect in fatty-acid metabolism with hypoglycaemia and organic aciduria. Lancet 2:986-987

26. Nyhan WL 1989 Nonketotic hyperglycinemia. In: Scriver CR, Beaudet AL Sly WS, Valle D (eds) The Metabolic Basis of Inherited Disease, 6th Ed. McGraw-Hill, New York, pp 743-753

27. Roe CR, Millington DS, Maltby DA, Kahler SG, Bohan TP 1984 L-Carnitine therapy in isovaleric acidemia. J Clin Invest 74:2290-2295

28. De Sousa C, Chalmers RA, Stacey TE, Tracey BM, Weaver CM, Bradley D 1986 The response to L-carnitine and glycine therapy in isovaleric acidemia. Eur J Pediatr 144:451-456

29. Bhan MK, Sazawal S, Bhatnagar S, Bhandari N, Guha DK, Aggarwal SK 1990 Glycine, glycyl-glycine and maltodextrin based oral rehydration solution. Acta Paediatr Scand 79.518-526

30. Treem WR, Stanley CA, Goodman SI 1989 Medium chain acyl-CoA dehydrogenase deficiency: metabolic effects and therapeutic efficacy of long-term Lcarnitine supplementation. J Inherited Metab Dis 12:112-119

31. Roe CR, Bohan TP 1982 L-Carnitine therapy in propionicacidaemia. Lance $1: 1411-1412$ 